\title{
Physico-chemical characterisation of sea buckthorn extracts for cosmetic use
}

\author{
Elisabeta CHIRILA* ${ }^{\mathrm{a} *}$ Elena OANCEA ${ }^{\mathrm{a}, \mathrm{b}}$ and Ioana Adina OANCEA ${ }^{\mathrm{b}}$ \\ ${ }^{a}$ Ovidius University, Department of Chemistry and Chemical Engineering, 124 Mamaia Blvd, 900527-RO \\ Constanta \\ ${ }^{b}$ Careless Beauty Organic Cosmetics Company, 42A Crinului Street, Romania
}

\begin{abstract}
The purpose of the paper is to present original results concerning characterization of different sea buckthorn (Hippophae rhamnoides L.) extracts and some original dermato-cosmetic products containing these extracts. Aqueous distillate from fruits and leafy branches, aqueous extract from seeds, fresh fruit juice and frozen fruit juice after 2 years of storage, ethanolic extracts of buds have been analyzed for the following parameters: total and organic acidity, oxidability, calcium and magnezium, $\mathrm{pH}$, conductivity, oxidation-reduction potential (ORP). The investigated sea buckthorn extracts have important contribution in care and treatment of skin diseases; during many years of experience in this field great benefits have been observed.

Taking into account also the results of previous studies of other researchers we consider that the ORP measurement of cosmetic mixtures could provide objective, cheap and reliable information about antioxidant activity of complex samples.
\end{abstract}

Keywords: sea buckthorn extracts, $\mathrm{pH}, \mathrm{ORP}$, original dermato-cosmetics

\section{Introduction}

Sea buckthorn (Hippophae rhamnoides L., Elaeagnaceae) is native from Eurasia and can grow wild or cultivated in crops, in Britain, China, Finland, France, Germany, India, Myanmar, Nepal, Pakistan, Romania and Russia. It is known as the "wonder plant" because of the wide types of applications in food, medicinal and pharmaceutical fields [1-5.].

The studies worldwide show that all parts of the plant are rich in different bioactive substances like carotenoids, flavonoids, tocopherols, free and esterified sterols, triterpenols, isoprenols, organic acids, vitamins [6-9], explaining the antibacterial, antioxidant, anti-inflammatory, antistress and immunomodulatory activity [10-13].

Sea buckthorn fruits, leaves, seeds are used to prepare medicinal preparations treating various diseases such as inflammation and gastric ulcers, cardiovascular diseases, radiation induced oxidative damage, high blood lipid symptoms, gingivitis, eye and skin ailments [14, 15]. In addition to its medicinal applications, and because of its protective effects on the skin, sea buckthorn oil is also used for cosmetics, including sun blocks [16]. The plant extracts are complex, multicomponent mixtures and for cosmetic purposes two properties should be taken into account: $\mathrm{pH}$ and antioxidant activity.

Antioxidant activity, capacity, power, ability as synonyms is a complex parameter connected with concentration of substances or group of substances, much more informative than data on content of individual compounds in the investigated sample.

Starting from the skin benefits observed during many years of experience by using original cosmetic products containing sea buckthorn extracts, the study aims to characterize both of them (extracts and products). 


\section{Experimental}

\subsection{Sample preparation}

For experiments, the following parts of sea buckthorn harvested from the family farm, located in Tulcea County, Romania have been used: buds collected in February- March, fruits, seeds, branches and leaves collected in September-October.

Fresh or frozen juice, aqueous or alcoholic extracts have been prepared in order to determine physico-chemical properties as follows:

- aqueous distillates obtained from fruits and branches with leaves and fruits (further named sea buckthorn water): about $80 \mathrm{~kg}$ of fruit, fruit juice, branches and leaves were placed in a small-scale distillation boiler with $30 \mathrm{~L}$ water spring. A number of 5-7 consecutive fractions with a volume of 2-3 liters each have been collected for each composition (further named lot);

- aqueous distillate obtained from seed: $100 \mathrm{~g}$ of seeds were milled, added about $200 \mathrm{~mL}$ double distilled water and were subjected to extraction by steam distillation in a closed circuit; five fractions with volumes between 150-200 $\mathrm{mL}$ were collected.

- sea buckthorn juice obtained by fruits squeezing with a juicer; samples were analyzed as both fresh and frozen juice after 2 years of storage; there were separately tested pulp (that ferments) and the liquid (not fermenting);

- alcoholic extract of the buds: upon $200 \mathrm{~g}$ of freshly harvested buds were added $500 \mathrm{~mL}$ of ethyl alcohol, in a closed vessel dark colored. The mixture was manually mixed from time to time and analyzed after 60 days.

In the same time, original dermato-cosmetic products containing seabuckthorn extracts have been characterized following the procedures previously described [17-19].

\subsection{Measured parameters and analytical methods}

To characterize the investigated extracts there conventional chemical and physico-chemical methods were used.

Chemical parameters have been determined as follows:
- total and organic acidity by titration with $0.1 \mathrm{~N}$ sodium hydroxide solution in the presence of phenolphthalein or methyl orange;

- calcium and magnesium content by titration with $0.01 \mathrm{~N}$ complexan III under different conditions of $\mathrm{pH}$ in the presence of murexide and respectively erioT;

- dissolved organic substances (oxidability) by titration with $0.01 \mathrm{~N}$ potassium permanganate in acidic conditions.

$\mathrm{pH}$ and oxidation reduction potential (ORP) have been measured using a $\mathrm{pH} 300$ meter equipped with a combined electrode and the conductivity with a Consort K 610 conductometer.

\section{Results and Discussions}

To explain the beneficial effect that the seabuckthorn water has on skin, total and organic acidity, calcium and magnesium concentration, oxidability, $\mathrm{pH}, \mathrm{ORP}$ and conductivity were measured. In Table $\mathbf{1}$ are presented the obtained results.

Table 1. Physico-chemical characteristics of seabuckthorn water.

\begin{tabular}{|c|c|c|}
\hline Parameter & UM & Value \\
\hline Total acidity & $\mathrm{meq} / \mathrm{L}$ & 3.42 \\
\hline Organic acidity & $\mathrm{meq} / \mathrm{L}$ & 2.17 \\
\hline Calcium & $\mathrm{mg} / \mathrm{L}$ & 1.44 \\
\hline Magnezium & $\mathrm{mg} / \mathrm{L}$ & 0.20 \\
\hline Oxidability & $\mathrm{meq} / \mathrm{L}$ & 12.35 \\
\hline $\mathrm{pH}$ & units & $3.23-4.29$ \\
\hline ORP & $\mathrm{mV}$ & $156-192$ \\
\hline Conductivity & $\mu \mathrm{S} / \mathrm{cm}$ & 103.4 \\
\hline
\end{tabular}

Low values of $\mathrm{pH}$ are correlated with the content of acidic species. Studies presented in literature show that seabuckthorn juice, for example, contains significant concentrations of organic acids such as malic and quinic acid [7]. The predominance of organic acidity assures the high hydrating effect for all types of skin [20].

The $\mathrm{pH}$ and ORP variation of aqueous distillates from fruits and leafy branches for the first 4 fractions of three prepared lots are presented in Fig.1. and Fig. 2. 
It can be observed that, during the distillation process of the same mixture of plant material, $\mathrm{pH}$ decreases from 0.3 to 0.6 units and ORP increases by $14-50 \mathrm{mV}$.

$$
\square 1 \square 2 \text { 日 } \square 4
$$

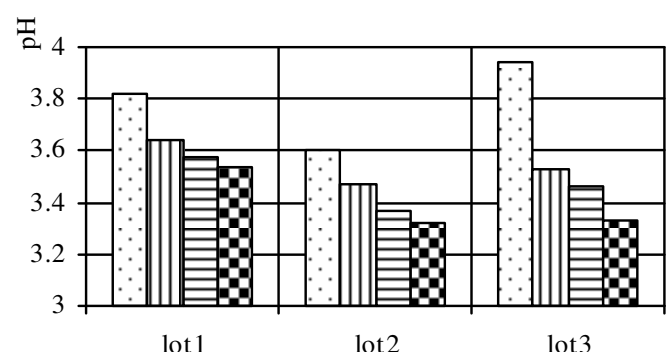

Fig.1. pH variation for different seabuckthorn aqueous extracts from fruits and leafy branches during distillation $(1,2,3$ and 4 represent fractions of each lot)

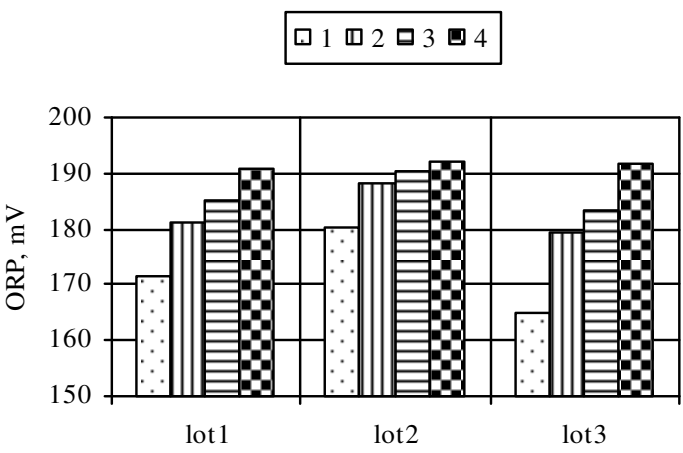

Fig.2. ORP variation for different seabuckthorn aqueous extracts from fruits and leafy branches during distillation $(1,2,3$ and 4 represent fractions of each lot).

Figures 3 and 4 show the variation of the same parameters ( $\mathrm{pH}$ and ORP) for the aqueous distillate obtained from seabuckthorn seeds.

In the case of seeds aqueous distillate, the same evolution is observed during the distillation process: $\mathrm{pH}$ decreasing and ORP increasing. The initial $\mathrm{pH}$ and ORP values are higher, respectively lower than in the case of fruits and leafy branches aqueous distillate.

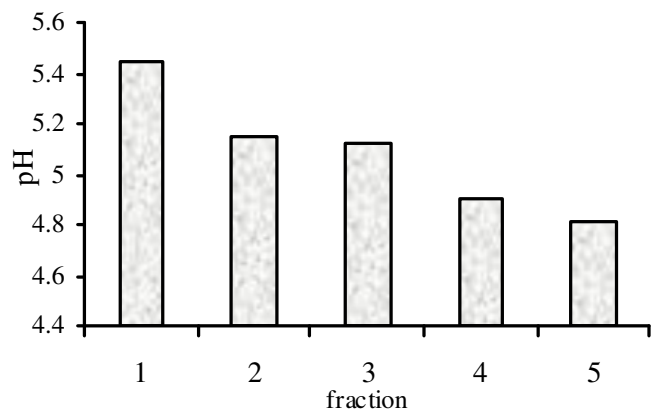

Fig.3. $\mathrm{pH}$ variation of aqueous extracts from seabuckthorn seeds during distillation (five fractions).

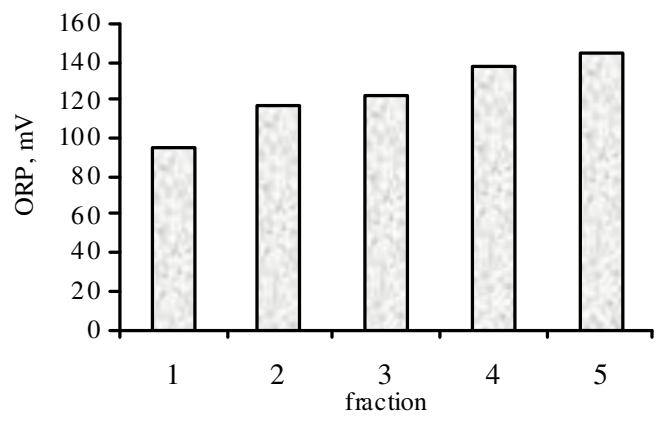

Fig.4. ORP variation of aqueous extracts from seabuckthorn seeds during distillation (five fractions).

Seabuckthorn juice had $\mathrm{pH}$ values around 2.5 units and ORP higher than $220 \mathrm{mV}$ (see Table 2), being the most acidic extract of the studied plant material.

Table $2 \mathrm{pH}$ and ORP of sea buckthorn fruit juices

\begin{tabular}{|l|c|c|}
\hline \multicolumn{1}{|c|}{ Type } & $\begin{array}{c}\mathrm{pH}, \\
\text { units }\end{array}$ & $\begin{array}{c}\text { ORP, } \\
\mathrm{mV}\end{array}$ \\
\hline Fresh juice 2011 & 2.56 & 252 \\
\hline 5 days left to ferment juice & 2.77 & 229 \\
\hline Frozen juice 2011 & 2.81 & 229 \\
\hline Frozen juice 2011 after two years & & \\
Pulp & 2.56 & 239 \\
Liquid (does not ferment) & 2.55 & 240 \\
\hline
\end{tabular}


Recently, ORP values are used as global indicator to assess changes in the effectiveness of drugs [21] or are proposed to describe the antioxidant activity of complex mixtures [22].

As a consequence, our investigations include also the $\mathrm{pH}$ and ORP measurement for some original [17-19] dermato-cosmetic products containing extracts of seabuckthorn (Table 3).

Table $3 \mathrm{pH}$ and ORP of original dermato-cosmetics containing sea buckthorn extracts

\begin{tabular}{|l|c|c|}
\hline \multicolumn{1}{|c|}{ Product } & $\begin{array}{c}\mathrm{pH}, \\
\text { units }\end{array}$ & $\begin{array}{c}\text { ORP, } \\
\mathrm{mV}\end{array}$ \\
\hline Cream Careless beauty 2007 & 4.43 & 151.3 \\
\hline Cream Careless beauty 2009 & 5.00 & 115.8 \\
\hline Cream Careless beauty 2011 & 4.29 & 156.8 \\
\hline Compress Careless beauty 2011 & 3.13 & 225.0 \\
\hline Oil Careless beauty 2011 & 4.79 & 129.5 \\
\hline Ethanolic buds extract & 5.00 & 66.0 \\
\hline
\end{tabular}

The original dermato-cosmetic products are entirely natural, with no chemicals added and have nourishing, revitalising and restorative action that promote tissue regeneration, reducing age-induced skin wrinkling and premature skin aging.

Figures 5 and $\mathbf{6}$ present photos of skin before and after four months of cosmetic treatment using the investigated original dermato-cosmetic products.

The first case represents a female 34 years old which presented at the start of the treatment with Careless Beauty products skin changes due to thyroid disorders (Hashimoto) and vitiligo: the presence of pigment spots on the face, arms and back. After four months of daily use of the above products the skin was regenerated 35-40 \% (Fig.5).

Total regeneration of the skin occurred after one year of treatment.

The second case is of a teenager aged 15 years, with juvenile acne; the skin showed numerous pustules with painful nodules and deep abscesses.

After a month of Careless Beauty products daily applications, skin regenerates at a rate of $2530 \%$ and after four months of treatment, staphylococcal infection has been eliminated completely and 50\% of the scars were regenerated (Fig.6).

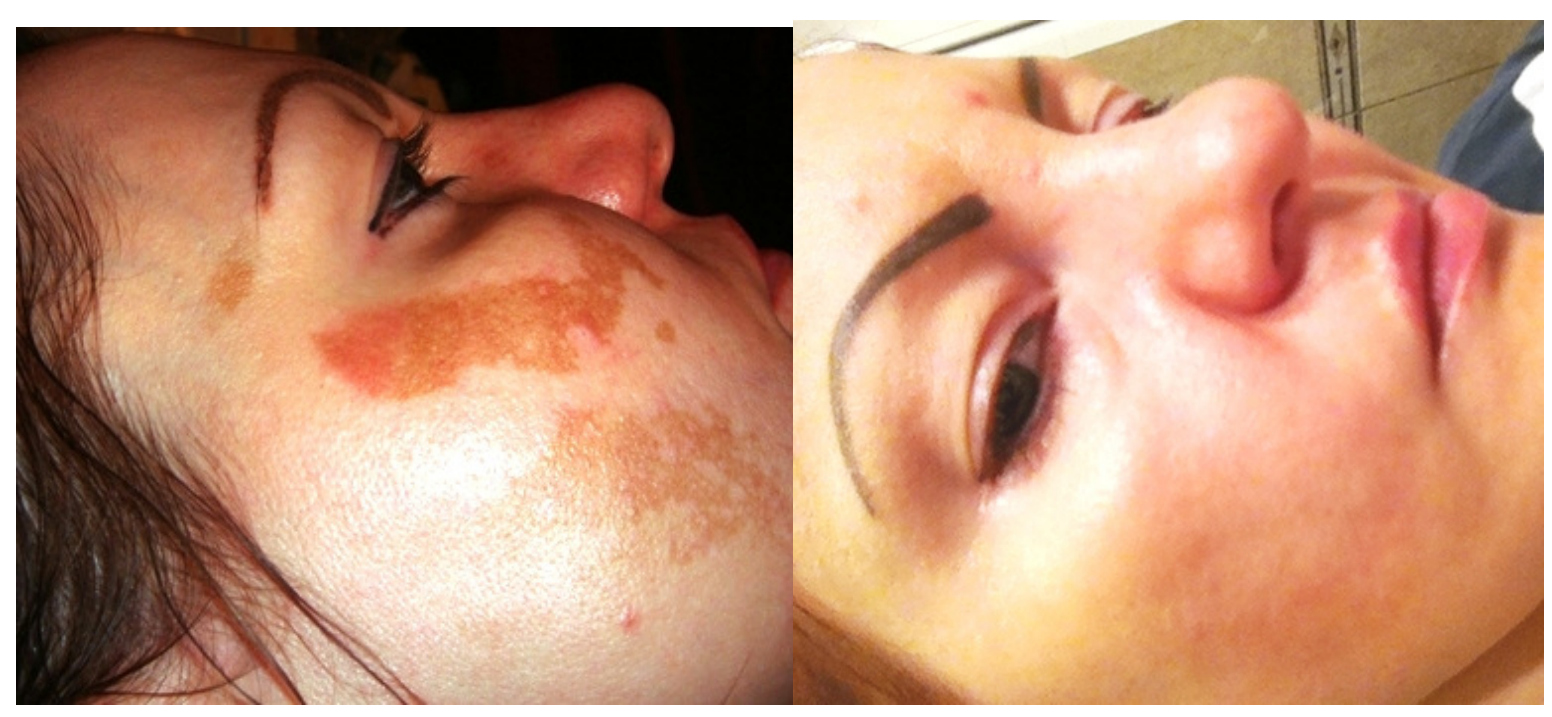

Fig. 5. The skin appearance of 34 years old person with pigment spots before and after 4 months of treatment with original dermato-cosmetic products containing seabuckthorn extracts 


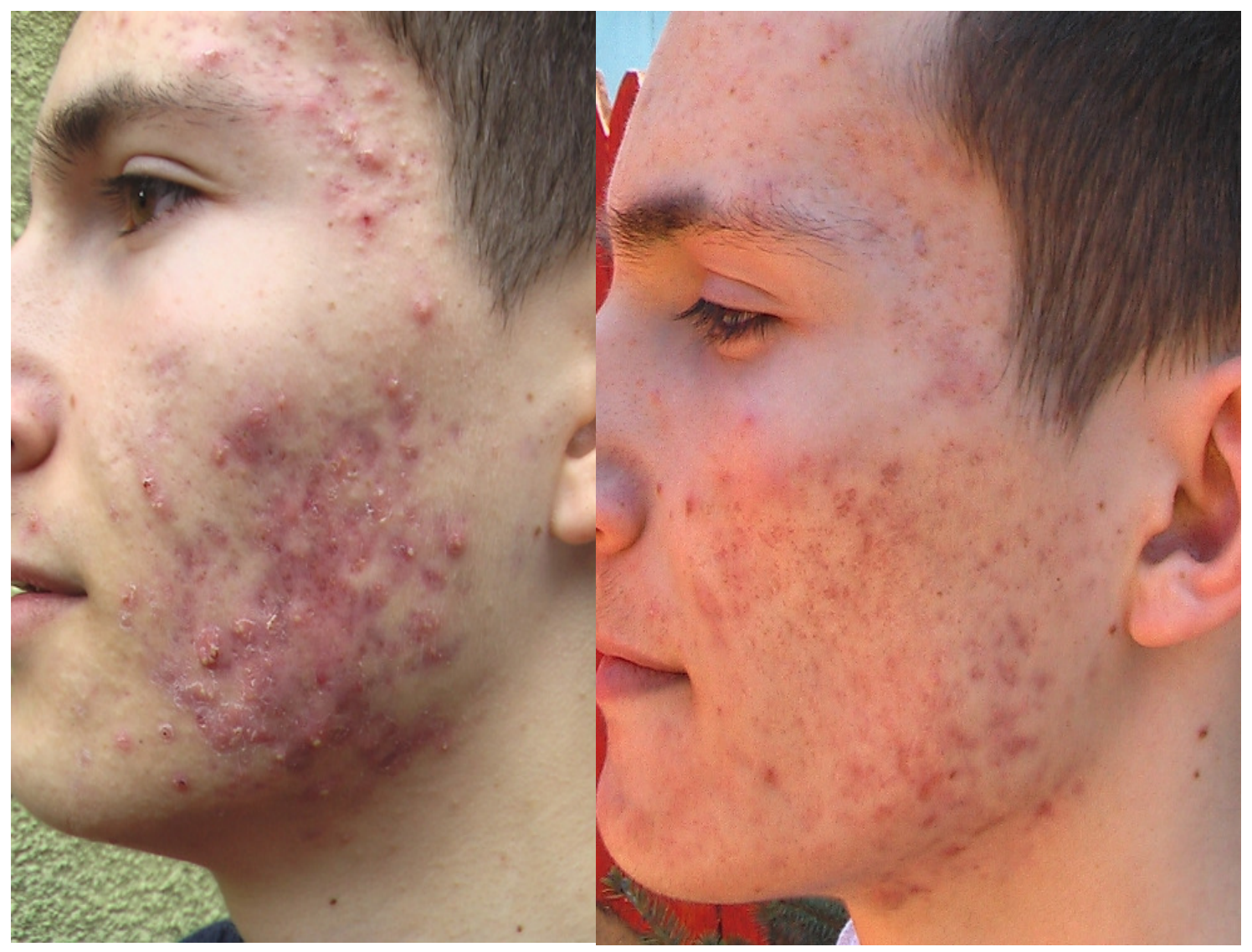

Fig.6. The skin appearance of 15 years old person with juvenile acne before and after 4 months of treatment with original dermato-cosmetic products containing seabuckthorn extracts

\section{Conclusions}

Starting from the skin benefits observed during many years of experience by using original cosmetic products containing sea buckthorn extracts, the study aimed to characterize both of them (extracts and products).

Interesting shapes of $\mathrm{pH}-\mathrm{ORP}$ evolution have been observed to all studied products. Low $\mathrm{pH}$ values explain the hydrating action and ORP data are related to bioactive compounds.
Taking into account also the results of previous studies of other researchers we consider that the ORP measurement of cosmetic mixtures could provide objective, cheap and reliable information about antioxidant activity of complex samples.

\section{References}

* E-mail address: echirila@ yahoo.com

[1]. W. R.Schroeder and Y. Yao, Sea-buckthorn, a promising multi-purpose crop for Saskatchewan. Prairie Farm Rehabilitation 
Administration (P.F.R.A.) Shelterbelt Centre. Indian Head, SK. (2003).

[2]. K.Laos, T.Lougas, A.Mandmets and R.Vokk, Food Science and Emerging Technologies 8, 395-398 (2007)

[3]. M.Sajfrtova and H. Sovova Procedia Engineering 421682 - 1691 (2012).

[4]. M.Danihelova, J.Viskupičova and E. Šturdik, Acta Chimica Slovaca 5, 59-69 (2012).

[5]. G.Li, X.Zeng, Y.Xie, Z.Cai, J.C.Moore, X.Yuan, Z. Cheng and G. Ji, Fitoterapia 83 182-191 (2012).

[6]. C.Sava, E.Chirila and L. Bucur, Proceedings " $12^{\text {th }}$ Romanian Conference on Chemistry and Chemical Engineering”, 89-92 (2001).

[7]. Zeb A., Pakistan Journal of Nutrition 3(2), 99106 (2004).

[8]. D.Gutzeit, V. Wray P. Winterhalter and G. Jerz, Chromatographia, 65, 1-7 (2007).

[9]. J. Emer, H.Waldorf and D. Berson, Semin Cutan Med Surg 30, 148-155 (2011).

[10]. L. Ganju, T.Y Padwad, R. Singh, D. Karan, S. Chanda, M.K. Chopra, P. Bhatnagar, R.Kashyap, and R.C. Sawhney, International Immunopharmacology 5 1675-1684 (2005).

[11]. A.S. Chauhan, P.S. Negi and R.S. Ramteke, Fitoterapia 78, 590-592 (2007)

[12]. P.S.Negi, Chauhan A.S., G.A. Sadia, Y.S. Rohinishree and R.S. Ramteke, Food Chemistry 92 119-124 (2005).

[13]. M. Mendez, R.Rodríguez, J.Ruiz, D.Morales Adame, F.Castillo, F.D.Hernández Castillo and C.N. Aguila, Industrial Crops and Products 37, 445- 450 (2012).
[14]. S.Saggu, H.M. Divekar, V. Gupta, R.C. Sawhney, P.K. Banerjee and R. Kumar, Food and Chemical Toxicology 45, 609-617 (2007).

[15]. S. Saggu and R. Kumar, Phytomedicine 15, 437-446 (2008),

[16]. *** http://seabuckthorn.co.uk/ sea buckthornhealth-benefits.html

[17]. E. Oancea and D. Oancea, Composition for natural cosmetic treatment RO Patent No B1119065 (2004)

[18]. E. Oancea and D. Oancea, Hydrating creme, anti wringles, healing with regenerating effect RO Patent No127165 (2014)

[19]. A.I. Oancea and T.N Oancea, Water from seabuckthorn fruits (patent request submitted to OSIM, A00524/6.11.2012)

[20]. B.A.Green, R.J. Yu and E.J.,Van Scott, Clinics in Dermato-logy 27, 495-501 (2009).

[21]. Y. Pan, R.V. Tikekar and N. Nitina, International Journal of Pharmaceutics 450, 129137 (2013).

[22]. Kh.Z.Brainina, A.V. Ivanova, E.N. Sharafutdinova, E.L. Lozovskaya and E.I. Shkarina, Talanta 71, 13-18 (2007).

Submitted: Octomber $9^{\text {th }} 2014$ Accepted in revised form: November $16^{\text {th }} 2014$ 